\title{
Epileptic Syndromes Related to the Hypothalamic Hamartomas
}

\author{
Behzad Saberi* \\ Medical Research, Esfahan, Iran \\ *Corresponding author: Behzad Saberi, Medical Research, Esfahan, Iran
}

\section{Mini Review}

Gelastic epilepsy, progressive cognitive decline, behavioral disturbances, and precocious puberty, can be the symptoms of the hypothalamic hamartomas [1-3]. Gelastic seizures or the pressure to laugh phenomenon, are the hallmark of the hypothalamic hamartoma's epilepsy. These seizures usually begin in the neonatal period and will develop to seizures types which would be catastrophic and refractory in their nature. Recurrent brief seizures which would be initiated by grimacing or laugher which is not emotional in nature, are the characteristics of the gelastic fits [4-6]. Although gelastic seizures are the main seizure types which are related to the hypothalamic hamartomas, but there are some other types of seizures which are related to such hamartomas and they usually would be more problematic and disabling in nature in comparison with gelastic seizures. Drop attacks and falling seizures, partial complex seizures, atypical absences, generalized tonic-clonic seizures and tonic seizures with or without secondary generalization, are the examples of other seizure types which can be occurred in the patients with hypothalamic hamartomas.

In the adult patient's group with hypothalamic hamartomas, the severity of the seizures would be less than ones in the pediatric patient's group. Cognitive and behavioral problems are also less common in the adult patient's group [7]. These findings suggest that hypothalamic hamartomas related seizures, are more severe in their nature in the padiatric patients' group.

\section{References}

1. Arzimanoglou AA, Hirsch E, Aicardi J (2003) Hypothalamic hamartoma and epilepsy in children: illustrative cases of possible evolutions. Epileptic Disord 5: 187-199.

2. Cascino GD, Andermann F, Berkovic SF (1993) Gelastic seizures and hypothalamic hamartomas: evaluation of patients undergoing chronic intracranial EEG monitoring and outcome of surgical treatment. Neurology 43: 747-750.

3. Delalande O, Fohlen M (2003) Disconnecting surgical treatment of hypothalamic hamartoma in children and adults with refractory epilepsy and proposal of a new classification. Neurol Med Chir (Tokyo) 43: 61-68.

4. Kuzniecky R, Guthrie B, Mountz J (1997) Intrinsic epileptogenesis of hypothalamic hamartomas in gelastic epilepsy. Ann Neurol 42:60-67.

5. Harvey AS, Freeman JL (2007) Epilepsy in hypothalamic hamartoma: clinical and EEG features. Semin Pediatr Neurol 14: 60-64.

6. Biesecker LG (2003) Heritable syndromes with hypothalamic hamartoma and seizures: using rare syndromes to understand more common disorders. Epileptic Disord 5:235-238.

7. Fenoglio KA, Wu J, Kim DY (2007) Hypothalamic hamartoma: basic mechanisms of intrinsic epileptogenesis. Semin Pediatr Neurol 14:5159. 
This work is licensed under Creative Commons Attribution 4.0 License

To Submit Your Article Click Here: Submit Article

DOI: $10.32474 /$ PAPN.2020.02.000147

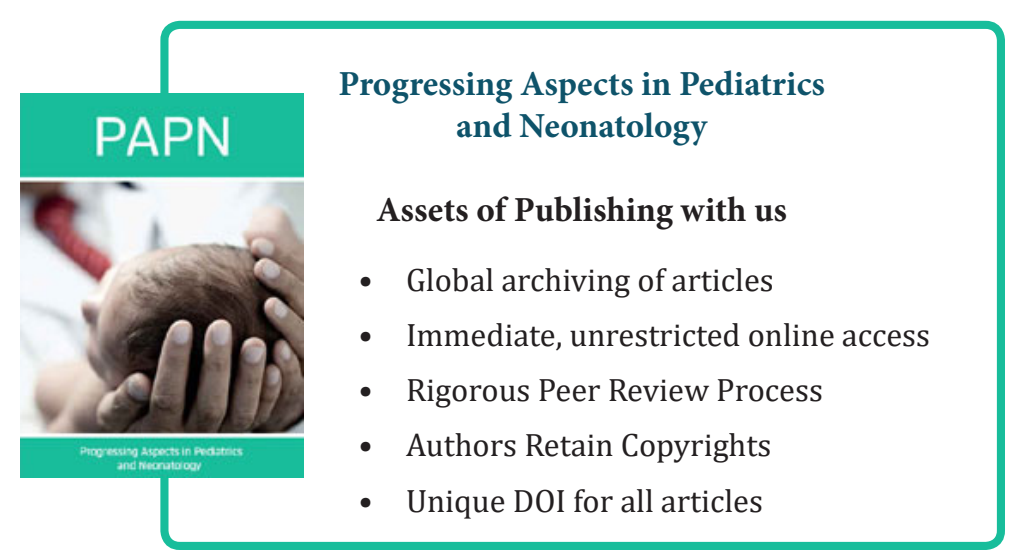

